\title{
Structural Diagnosis of Personality Pathology: Kernberg's Object Relations Model
}

\author{
In-Soo Lee \\ In-Soo Lee MD's Psychiatric and Psychoanalytic Clinic, Seoul, Korea
}

\section{인격 병리의 구조적 진단: Kernberg의 대상관계 모델을 중심으로}

\author{
이 인 수 \\ 이인수 정신건강의학과 정신분석클리닉
}

\begin{abstract}
This paper reviews the structural diagnosis of personality pathology based on Kernberg's object relations theory. It examines levels of integration of the five psychological structures such as 1) identity (sense of self and others), 2) major defense mechanisms (level of defensive operations), 3) reality testing, 4) quality of object relations, and 5) moral functioning. It is a diagnostic model that is especially valuable in identifying and differentiating the borderline personality organization (BPO). Patients organized at a low BPO level show severe identity pathology, splitting-based defenses, and unstable, highly affectively charged, polarized transferences, which significantly interfere with self-reflective capacity. For these reasons, it is suggested that psychoanalytic treatment should be modified to secure the therapeutic relationship and facilitate the integration of dissociated internal object relations in the here and now transference contexts.

Psychoanalysis 2019;30(4):89-97
\end{abstract}

KEY WORDS: Structural diagnosis · Personality pathology · Object relations theory $\cdot$ Borderline personality organization.

Received: March 24, 2019 Revised: June 16, 2019 Accepted: June 16, 2019

Address for correspondence: In-Soo Lee, MD

In-Soo Lee MD's Psychiatric and Psychoanalytic Clinic, 8 Apgujeong-ro 73-gil, Gangnam-gu, Seoul 06010, Korea

Tel: +82-2-517-7573, Fax: +82-2-517-7574, E-mail: psychoanalysis.lee@gmail.com

\section{서 론}

정신분석적 치료를 하는 임상가는 매일 환자의 증상과 그 아래 있는 인격 병리(personality pathology)를 깊이 이해하 고, 환자가 가진 심리적 역량을 정확하게 평가하고자 노력한 다. 하지만 인격 병리의 진단이 명확하지 않은 경우, 내담자 들의 심리적 취약성을 체계적이고 일관되게 분류하여 적절 한 치료 기법을 적용해가는 것은 매우 어려운 과제가 된다. 더불어 최근 정신분석이나 정신분석적 정신 치료의 대상이 높은 수준의 신경증 환자들뿐만 아니라, 정통 정신분석 기법 으로 분석이 어려웠던 다양한 결핍 환자들까지 확대되면서 (widening scope), 인격 병리와 정신구조에 대한 평가, 그에 맞는 치료 기법 적용의 중요성은 더욱 강조되어 왔다 $\left(\mathrm{Mc}^{-}\right.$

This is an Open Access article distributed under the terms of the Creative Commons Attribution Non-Commercial License (https://creativecommons.org/licenses/by-nc/4.0) which permits unrestricted non-commercial use, distribution, and reproduction in any medium, provided the original work is properly cited.
Williams 1994a, 1994b).

정신의학적 진단의 유형에는 기술적 진단(descriptive diagnosis)과 정신분석적 진단(psychoanalytic diagnosis)이 있 다. 기술적 진단은 Diagnostic and Statistical Manual of Mental Disorder System(DSM)이나 International Classification of Diseases system(ICD)이 대표적이며, 관찰되는 증 상의 조합을 통해 질환을 특정하고, 그 진단에 맞는 치료 기 법을 적용하는 의학적 접근 방법이다. 하지만 많은 경우 질 환들 사이에 증상이 겹치는 중복이환(comorbidity)의 문제 가 발생한다. 더불어 인격장애의 경우 경미한 신경증적 인격 장애는 진단에서 배제되고 심각한 인격장애 위주로 진단이 내려지는 한계가 있다. 2013년 개정된 DSM-5 인격장애 진 단 기준은 기존의 열 가지 인격장애 진단 카테고리를 유지하 면서도 section III에 향후 연구를 위한 새로운 형태의 인격 장애 진단 모델(a hybrid dimensional-categorical model)을 제안하고 있다. 즉, 여섯 가지 인격 병리 카테고리 모두에 대 하여 개인이 자기 자신(self)과 타인(others)을 어떻게 경험 
하는가를 평가하고 중등도 이상의 손상(impairments)이 있 을 때 인격장애로 진단하는 것이다. 이는 인격 병리에 대한 기술적 진단(categorical approach)이 갖는 한계를 보완하고 자 정체성(identity)이라는 정신구조(psychological structures)의 통합 수준에 따라 인격 병리를 분류하는 방식이며 (dimensional approach), Kernberg의 대상관계이론과 구조 적 진단(structural diagnosis)의 개념이 반영된 것이다 $(\mathrm{Ca}-$ ligor 등 2018).

\section{정신분석적 진단의 중요성과 유용성}

인격(personality)이란 한 개인이 타인과의 관계에서 드러 내는 지속적이고 습관적인 행동(behavior), 인지(cognition), 감정(emotion), 동기(motivation)의 독특한 패턴을 말한다. 인격장애(personality disorder)는 개인의 인격 특성(personality traits)이 지나치게 경직되어(rigidity), 만성적이고 심각 한 수준으로 일상생활을 방해하며, 그 자신이나 주변 사람들 에게 상당한 정도의 고통을 유발하게 될 때를 말한다. 정신 의학적으로는 인격장애에 대해서 두 가지 진단을 내리게 되 는데, 하나는 인격 병리의 수준을 구조적으로 진단하는 것이 고(severity of structural pathology: 신경증 수준의 인격, 경 계선 수준의 인격), 다른 하나는 인격의 스타일이나 유형을 기술적으로 진단하는 것이다(DSM-5 personality traits). McWilliams(1994a)는 환자가 가진 중심 주제(security, autonomy, identity)와 발달 단계에 따른 주요 불안과 갈등, 대상관 계 수준, 자기 정체감의 수준에 따라 세 가지 인격구조가 있 다고 말한다. 즉, 생애 초기 공생기 문제에 고착된 정신병적 수준(psychotic level)의 인격구조, 분리 개별화와 이자관계 문제에 고착된 경계선 수준(borderline level)의 인격구조, 삼자 관계의 오이디푸스 소망과 갈등이 주요 문제가 되는 신경증 수준(neurotic level)의 인격구조로 분류하였고, 각 수준에 따라 치료 목표, 전략, 기법을 수정하는 것이 임상적 으로 매우 유용하며 필요하다고 말한다(McWilliams 1994b). 특히 기술적 진단보다 인격 병리의 심각도를 구조적으로 진 단하는 것이 치료 기법, 예후 예측에 더욱 중요하다. 이와 관 련하여 Sugarman(2007)은 마음을 진단할 때 내용(contents) 보다 형식적 구조(formal organization) ${ }^{a}$ 를 보는 것이 더 중 요하다고 강조한다. 예를 들어 강박사고라는 내용은 원초적 으로 조직된 인격구조를 가진 사람에게도 나타날 수 있고, 성숙한 신경증적 수준의 인격구조를 가진 사람에게도 나타 날 수 있다. 반면에 자기 관찰 능력(capacity for self-reflection), 감정 조절 능력(capacity for affect regulation), 자기애

a본 논문에서 저자는 psychological structure와 psychological organization을 모두 정신구조로 해석하였다.
적 조절 능력(capacity for narcissistic regulation), 심리 내적 갈등을 가질 수 있는가(intrapsychic conflict) 등의 구조적 측면은 예후가 더 양호한 신경증 수준의 환자와 예후가 더 좋지 않은 원초적 수준의 인격구조를 가진 환자를 구별할 수 있게 한다는 것이다(Sugarman 2007).

본 논문에서는 정신구조란 무엇이며, 구조적 진단은 어떤 것인지를 정의하고, $\mathrm{DSM}-5$ 인격장애 진단 기준의 근간이 된 Kernberg의 대상관계이론을 중심으로 인격(personality) 과 인격 병리(personality pathology)를 구조적으로 진단하 는 다섯 가지 주요 영역을 고찰한다. 또한 대표적인 이론가 인 Kernberg와 McWilliams의 구조적 진단에 근거한 치료적 접근 방향과 기법을 간략하게 소개하고자 한다.

\section{본 론}

\section{정신구조의 정신분석적 의미}

Freud(1923)는 그의 책 『The ego and the id」에서 지형학 적 이론(topographic theory)이 갖는 한계들을 해결하고자 구조이론(structural theory)을 제시하였다. 즉, 마음의 상태 와 인간의 행동은 정신구조들(mental structures; 이드, 자아, 초자아) 간의 내적 갈등과 타협에 따라 결정된다는 것이다 (Freud 1923). 여기서 정신구조는 주체적으로 작동하는 심 리 내적 에이전시(agency) ${ }^{\mathrm{b}}$ 를 의미했다. 이후 정신구조의 개 념은 변화되어 왔으며 특히, Rapaport(1967)는 인간의 정신 과정(mental processes)은 조직화되어 안정적인 기능단위 (functional units)를 형성하게 되고, 형성된 기능단위들 간에 관계가 형성되면서 더 정교한 정신구조가 조직된다(organized)고 하였다. 현대 정신분석에서 정신구조는 특정 상황에 서 반복적, 예측 가능한 패턴으로 활성화되는 정서적, 인지적 정신기능으로 정의된다(Lenzenweger와 Clarkin 2005). 정신 구조의 형성은 이전 단계 구조들의 단순한 총합이 아니고, 각 발달 시기별로 심리 내적 요인과 외적 요인의 영향을 받 아 역동적으로 새로운 조직으로 발전한다. 즉, 정신구조는 불연속적이고, 위계적으로 조직된다. 형성된 정신구조는 시 간이 감에 따라 안정화되어 잘 변화하지 않지만, 성숙 과정, 인생의 경험, 성공적인 치료에 따라 수정되기도 한다. 정신 구조는 치료자나 환자 모두 직접 관찰할 수 없고, 오직 증상,

\footnotetext{
${ }^{\mathrm{b}}\ulcorner$ Agency: Psychoanalytic Terms and Concepts」(Auchincloss 2012) 에 따르면, agency는 Freud가 지형학적 이론과 구조이론에서 제 시한 개념으로 마음 안에 있는 일련의 정신기능의 집합체를 뜻한 다. 현대적 의미의 agency는 개인의 필요, 소망, 기타 동기들을 실 현하는 주체이며, 현대 정신분석의 목표는 개인이 agency로서 스 스로 선택할 수 있는 능력(capacity for choice)을 키우는 것이다.
} 
특정 행동 패턴, 대인관계의 양상, 환자의 주관적 경험들을 근거로 기저에 어떠한 정신구조가 있을 것인지, 이러한 정신 구조가 어떻게 다양한 방식으로 영향을 주는지를 체계적으 로 추론해 나갈 수밖에 없다. 예를 들어 양심(conscience)은 도덕적 기준과 관련된 심리 과정들로 이루어진 정신구조이 다. 양심이라는 정신구조는 도덕적 행동, 죄책감, 도덕적 이 상과 가치를 따르는 것으로 드러난다. 도덕과 관련된 다양한 경험이 조직화되어 양심이라는 특정한 심리적 과정, 즉 정신 구조를 이룬다. 방어기제 역시 반복적으로 사용되고, 예측 가능한 경향성을 가진 정신구조이다. 개인이 고통스러운 상 황에 직면할 때 발생하는 감정적 충격을 최소화하려는 행동 들 아래에는 이러한 방어기전이 정신구조로 자리잡고 있다 (Caligor와 Clarkin 2010). 대상 항상성(object constancy) 역 시 정신구조이다. 대상 항상성은 외부 대상과의 관계에서 단 순하고, 흔적적이며, 암시적인 수준의 경험들이 점차 통합되 고, 복잡해지고, 점차적으로 안정적인 자기 표상과 대상 표상 으로 발전하고, 이 표상들이 조직되어 안정화된 것이다. 대상 항상성을 획득하게 되면 자아 경계의 형성, 정체성의 발달, 외부 현실에 더욱 효과적, 효율적으로 적응할 수 있는 능력을 갖게 된다(Sugarman과 Jaffe 1990). 더불어 오이디푸스 콤 플렉스와 관련된 무의식적 갈등믄 내재화된 대상관계도 정신 구조로 본다. 신경생물학적으로 정신구조는 특정한 상황에 서 활성화되는 신경회로(neural circuit) 혹은 연관 회로망 (associational networks)과 관련되어 있을 것이다(Westen과 Gabbard 2002).

\section{구조이론과 대상관계이론의 통합}

1960 년대 발달 심리학의 발전과 더불어 아이와 양육자 간 의 상호작용이 정신구조의 발달에 미치는 영향이 크게 주목 받기 시작했다. 그 결과 인간의 마음은 자신(self)과 타인(object)의 내적 표상들(internal representations)로 구성되어 있 으며, 이러한 내적 표상들은 점차 내면화(internalized)되고, 체계화(organized)되어 지속적인 패턴으로 작동한다는 대상 관계이론이 발전하게 된다. 즉, 대상관계이론에서는 생애 초 기 중요 대상과의 관계 패턴이 개인의 심리적 동기(motiva-

${ }^{\mathrm{c}} \mathrm{Freud}$ 의 정신성적 발달이론에서 제안된 개념으로 infantile genital phase의 최고조인 3 6세에 삼자관계에서의 심리적 갈등, 환상, 내 적 대상관계, 동일시, 초자아 형성의 복잡한 조합으로 형성된 오이 디푸스 콤플렉스는 어린 시절에 마음에 내면화되고, 성인기까지 지 속적으로 영향을 미치므로 정신구조로 볼 수 있다. 하지만 현대 정 신분석에서 오이디푸스 콤플렉스가 인간에게 보편적으로 발생하 는 정신구조인가(universality of Oedipus complex)?에 대해서는 논란이 있다. tion), 기능(function), 발달(development)의 중심 양상을 결 정한다고 주장한다. 대상관계이론에서 주장하는 핵심 이 론은 다음과 같다. 1) 내적 대상관계는 대개 무의식적이다. 2) 성적 욕구나 공격적 충동 이외에 대상을 추구하는 소망 (애착 추구)도 인간의 고유한 욕구이다. 3) 인간의 경험은 자 기 표상, 대상 표상, 이 둘 사이의 상호작용으로 이루어지는 데 점차 조직화되어 안정적인 마음의 구조를 만든다. 4) 아 이와 양육자 간의 상호작용은 초자아뿐만 아니라 다른 모든 정신구조의 발달을 가져온다. 5) 아이와 양육자 간의 전오이 디푸스(pre-Oedipal) 상호작용은 오이디푸스(Oedipal) 상호 작용만큼이나 중요하다(특히 대상관계이론은 전오이디푸스 시기 병리가 다음 단계인 오이디푸스 시기의 병리로 이어진 다는 점을 강조한다). 6) 구조이론이 오이디푸스 갈등에 대 한 해석과 통찰을 강조하였다면, 대상관계이론에서는 치료 자-환자 관계가 변화를 일으키는 중요한 요소로 작용한다 는 것을 강조한다. 7) 환자의 내면 세계에 대한 정보로서의 역전이를 강조하며, 이를 치료적으로 이용하는 것을 강조한 다(Auchincloss 2015). 한편, 대표적인 대상관계 이론가인 Jacobson과 Kernberg는 정통 분석이론의 갈등-방어 모델과 자아심리학, 구조이론을 비판적으로 계승하면서 처음으로 대상관계이론을 이에 통합하였다. 이들은 생애 초기 대상관 계의 내재화와 조직화의 과정을 거치면서 더 상위의 정신구 조인 이드, 자아, 초자아가 조직화된다고 설명했다(kernberg 1976).

\section{정신구조의 발달과 관련한 Kernberg의 주요 이론}

Kernberg는 전통적 욕동 이론(traditional dual instinct theory), Freud의 구조이론(structural model), Klein과 Fairbairn의 대상관계이론, Jacobson, Mahler, Erikson 등이 발 전시킨 자아심리학의 발달적 관점(developmental perspectives of American ego psychology) 등을 성공적으로 통합 하였고, 대상관계 모델에 근거하여 다양한 스펙트럼의 인격 병리(personality pathology)를 정신구조의 수준에 따라 분류 하고, 그에 적합한 정신분석적 치료 기법을 발전시켜 왔다. Greenberg와 Mitchell(1983)은 Kernberg가 제시한 정신구조 의 발달 모델을 다음과 같이 요약하고 있다. Jacobson, Mahler 의 이론처럼 태어날 때 유아는 자기와 대상의 구분이 없으며, 만족감 혹은 불만족감이라는 두 가지 모호한 정동 상태(affective states) 사이를 오간다. 아이의 첫 번째 주요 발달 과업 은 자기와 대상을 명료하게 구분하는 것이다. 자기와 대상 사 이에 분명한 경계가 획득될 때, 유아는 자기의 이미지와 대상 의 이미지를 구분할 수 있게 된다. 첫 번째 과제의 실패는 정 신병적 상태(psychotic state)의 결정적인 전구체(precursor) 
가 된다. 두 번째 발달 과업은 분열(splitting) 방어기제의 극 복이다. 분열은 발달적으로 정상적인 방어기제인데, 유아는 자기와 대상을 구분한 뒤에 두 가지 서로 다른 강렬한 감정 경험들을 분리하여 경험한다. 이후 분열 방어기제를 억압 방 어기제로 대체하면서 자신과 대상에 대한 긍정적 이미지와 긍정적 감정(libidinal affects)과 부정적 이미지와 부정적 감 정(aggressive affects)을 통합하고 함께 경험할 수 있는 능력 을 획득하는 것이 두 번째 과제가 된다. 이것에 성공하면 전 체 대상 경험(whole object experience)이 가능하게 된다. 하 지만 분열 방어기제 극복에 실패하면 병적인 분열 방어기제 가 성인기까지 지속되는 경계선 병리가 발생한다(Greenberg 와 Mitchell 1983). Kernberg의 대상관계이론은 대상으로부 터 분화할 수는 있었지만 자기와 대상의 긍정적인 면과 부정 적인 면을 통합하는 데 실패한, 대상 항상성(object constancy)의 문제를 가진 심한 인격장애 환자의 치료에 임상적으 로 매우 유용하다.

Kernberg와 Caligor(2005)에 따르면 인간의 주관적 경험 에는 세 가지 특정한 구성 요소들이 있는데, 자기 표상(selfrepresentation)-대상 표상(object-representation)-그 사이 를 연결하는 특정한 정동 상태(particular affect sate)가 그것 들이다. 그는 이 세 가지로 구성된 경험의 단위를 인지정동 단위(cognitive-affective unit)라고 이름하였다. 다양한 관계 양상에서 경험된 인지정동단위는 상위 정신구조(higher order structure)를 세워가기 위한 기본 요소(building block)로 서의 역할을 한다. 예를 들어 정체성(identity)이라고 하는 상위 정신구조는 자기(self)와 대상(other)에 대한 주관적 경 험과 관련된 대상관계들이 조직화된 것이고, 양심(conscience)은 금지와 이상적 가치 등과 관련된 대상관계들이 조직화된 것이다. Kernberg에 따르면 이러한 내적 대상관계 의 형성은 생애 초기부터 형성되기 시작하고, 이것의 형성에 영향을 주는 주요 요소들로서 1) 타고난 정서적 기질적 성향 (inborn affect dispositions), 2) 양육자와의 애착 양상을 들 었다(Kernberg와 Caligor 2005).

특정한 관계적 맥락은 특정한 내적 대상관계를 활성화시 키고, 대인관계에서 개인의 행동과 감정에 영향을 주게 된 다. 예를 들어 무기력하고 약한 어린아이 같은 자기(victimized self), 강력한 힘을 가진 위협적인 부모(persecuting object)의 대상관계와 공포감(fear, hypervigilance)의 정동을 내면화한 사람은 침범과 통제에 훨씬 과민한 불안 반응을 보 일 것이다. 한편 Kernberg는 내면화된 대상관계를 강조하고 있지만 개인이 가진 심리적 갈등, 방어, 환상들과 같은 정신 역동적 요소들도 개인의 경험에 영향을 준다고 언급했다. 예 를 들어 부모를 해치고 싶은 공격적인 충동을 가진 개인은
죄책감을 피하기 위해 '화가 나고 공격적인 것은 내가 아니 라 부모다. 나는 약하고 두려워하는 아이다!'라고 느끼게 된 다(projection). 이것은 특정한 대상관계가 공격적 충동에 대 한 내적 갈등을 회피하고, 심리적 고통을 줄이기 위해 방어적 으로 사용된 예이다.

\section{대상관계 모델에 기반한 인격 병리의 구조적 진단}

Kernberg 등은 대상관계 모델을 기반하여 인격구조(personality organization)를 다음 네 가지 수준으로 나누었다. 1) 정상 인격(normal), 2) 신경증 수준의 인격구조(neurotic personality organization), 3) 높은 수준의 경계선 인격구조 (high level borderline personality organization), 4) 낮은 수 준의 경계선 인격구조(low level borderline personality organization). 이들은 다섯 가지 핵심 정신구조(psychological structures)의 수준에 따라 진단 분류된 것이다(Kernberg 1970, 1984; Kernberg와 Caligor 2005; Caligor와 Clarkin 2010). 저자는 Kernberg 등이 제시한 정체성(identity, sense of self and others), 주요 방어기제(predominant defensive operations), 현실 검증력(reality testing), 대상관계의 질(quality of object relations), 도덕 기능(moral functioning)이라는 다섯 가지 정신구조의 개념과 수준별 특징을 소개하고, 이러 한 인격 병리의 수준이 갖는 임상적 의미를 살펴보고자 한다.

\section{정체성(Identity)}

내적 대상관계는 점진적으로 조직화되어 고차원의 정신 구조인 통합된 자기 정체감(integrated sense of self)을 형성 한다. 그 결과 주관적으로 경험되는 자기(subjective sense of self)는 보다 복잡해지고, 세밀하게 분화되고, 시간이 감에 따 라 유연하고 현실적으로 경험된다. 정상 인격(normal personality)이나 신경증 수준의 인격구조(neurotic level personality organization, $\mathrm{NPO}$ )를 가진 사람은 분명하고 통합된 정체성(normal identity)을 가지며, 타인에 대한 내적 경험도 보다 정확하게 지각된다. 그 결과 스스로의 가치, 취향, 의견, 믿음 등을 확고하게 가지고, 직업적 영역, 지적 영역, 유희적 영역(recreational)에 자신을 투자할 수 있게 된다(Kernberg 와 Caligor 2005).

반면, 경계선 수준의 인격구조(borderline level personality organization, $\mathrm{BPO}$ )를 가진 사람은 자신과 대상에 대하 여 “all good or all bad”로 지나치게 극단적인 내적 대상관 계를 가지고 있으며 대단히 긍정적이거나, 반대로 대단히 부 정적인 감정들이 각각에 결합되어 정체성 확산(identity diffusion)이 발생한다. 이 경우 강렬한 감정이 결합된 여러 대 상관계들은 통합이 이루어지지 않고, 매우 불안정하게 조직 
된다. 그 결과 자신과 중요한 대상에 대한 전반적이고 일관 된 이미지를 가질 수 없다. 그 대신 자기와 대상에 대한 주관 적 경험들은 분절되고, 양극화되고, 모호하고, 비현실적이 며, 연속성이 없고, 극단적이며, 불안정해진다.

정체성의 병리를 갖는 사람의 중요한 문제는 타인의 감정 을 정확하게 읽는 능력도 결여된다는 것이다(Donegan 등 2003; Wagner와 Linehan 1999). 그 결과 사회적 신호(social cue)에 적절하게 반응하지 못한다. 또 자신만의 취향, 의견, 가치관이 일관되지 않아서 주변 대상의 것을 쉽게 따르는 경향이 생기고, 주변 분위기에 따라 감정 변화도 극적으로 일어난다. 대상에 대한 감정의 분화가 세밀하지 않으며(allgood or all-bad/black or white), 대상에 대한 묘사는 단조 롭고, 감정의 복잡성이 부족하여 대상을 현실적으로 인식하 지 못한다. 이는 주로 경계선 인격장애에서 가장 명확하게 드러나는 병리이다. 하지만 다른 모든 심각한 인격장애들에 서도 어느 정도의 정체성 병리는 관찰된다.

경계선 수준의 인격구조(BPO)는 다시 높은 수준의 $\mathrm{BPO}$ (high level BPO)와 낮은 수준의 $\mathrm{BPO}($ low level BPO)로 나 눌 수 있다. 높은 수준의 $\mathrm{BPO}$ 는 낮은 수준의 $\mathrm{BPO}$ 에 비하여 정체성 장애(identity disturbances)가 심하지 않고, 보다 건 강하며, 현실적으로 타인을 경험하고, 타인과의 관계를 상호 적으로 유지해 가는 능력을 어느 정도 가진다. 도덕적 기능 이 유지되며, 공격성이 주된 문제가 아니다. 예후도 더 양호 하다. 높은 수준의 $\mathrm{BPO}$ 에는 DSM-5 의존성 인격장애, 연극 성 인격장애, 회피성 인격장애, 덜 병리적인 자기애적 인격 장애가 포함된다.

그에 비해 낮은 수준의 $\mathrm{BPO}$ 는 정체성 장애가 더 심각하 며, 현저한 관계 문제가 관찰되고, 일방적인 대인관계 패턴 을 보인다. 도덕성의 불균형이 심하고, 공격성이 자아에 잘 통합되지 않아 충동적으로 발현된다. 예후도 나쁜 편이다. 낮은 수준의 $\mathrm{BPO}$ 에는 DSM-5 편집성 인격장애, 조현성 인 격장애, 경계선 인격장애, 조현형 인격장애, 반사회성 인격 장애, 악성 자기애적 인격장애가 포함된다.

\section{주요 방어기제(Predominant defensive operations)}

확고한 정체성(consolidated identity)을 가진 사람의 방어 기제는 유연하고, 적응적이며, 내적/외적 현실의 왜곡이 거 의 없다. 반면 불안정한 정체성(less consolidated identity)을 가진 사람은 강렬한 심리적 스트레스에 대처하기 위해 내 적/외적 현실을 심각하게 왜곡하고 경직된 방어기제를 사용 한다. Kernberg는 인격구조의 수준에 따라 방어기제의 수준 도 다르다는 점을 강조하면서, 방어기제를 세 가지로 분류하 였다. 즉, 1) 성숙한 방어기제(mature defenses), 2) 억압을 기
반으로 하는 방어기제 혹은 신경증적 방어기제(repressionbased or "neurotic" defenses), 3) 분열을 기반으로 하는 방어 기제 혹은 원초적 방어기제(splitting-based or "primitive" defenses)가 그것이다(Kernberg 1976).

성숙한 방어기제는 심리적 고통을 줄이며 현실을 왜곡하 지 않고, 가장 합리적으로 대처할 수 있도록 돕는 방어기제 로서 예측(anticipation), 이타주의(altruism), 유머(humor), 승화(sublimation)가 있다(Vaillant 1993). 이러한 방어기제 를 사용하는 개인은 불안을 유발하는 상황의 모든 측면들을 의식으로부터 차단하지 않고 인식한다.

억압을 기반으로 하는 신경증적 방어기제는 자신의 주관 적 경험 중 갈등이 되거나 정서적 불편감을 유발할 수 있는 일부분을 의식으로부터 사라지도록 함으로써 회피한다. 억 압(repression), 반동 형성(reaction formation), 신경증적 투 사(neurotic projection), 전치(displacement), 고립(isolation of affect), 주지화(intellectualization) 등이 여기에 해당한다.

정상 인격이나 신경증 수준의 인격구조를 가진 사람은 갈 등 관련 내적 경험으로부터 자신을 보호하기 위해서, 성숙한 방어기제와 억압(repression)을 기반으로 하는 신경증적 방 어기제를 함께 사용한다. 그 결과 내적 경험 중 일부가 자신 의 전반적인 자기 정체감에서 분리되고(split off), 비교적 영 구히 의식 밖에 남아 있게 된다. 이것은 특징적인 인지적 패 턴, 인격의 경직성, 내적 현실의 미묘한 왜곡으로 이어져 주관 적 불편감을 유발한다(neurotic symptoms). 그러나 두드러진 이상 행동이나 파괴적인 행동으로 이어지지 않는다(Kernberg 와 Caligor 2005).

반면 경계선 수준의 인격구조(BPO)를 가진 사람들은 분 열(splitting)을 기반으로 하는 원초적인 방어기제를 주로 사 용한다. 즉, 갈등을 유발하는 서로 다른 내적 경험의 측면들 (mental contents)은 대상관계 상황에서 동시에 경험되지 않 고, 서로 연관성도 갖지 않는다(Kernberg 1976). 서로 다른 내적 측면들을 의식으로부터 분리시키지 않는 대신, 갈등과 불편감을 일으키는 서로 다른 내적 측면들 사이에 거리를 유 지하는 노력을 한다. 분열(splitting)을 기반으로 하는 원초적 인 방어기제에는 분열(splitting), 투사적 동일시(primitive idealization), 평가절하(devaluation), 전능 통제(omnipotent control), 부인(primitive denial) 등이 있다. Kernberg(1984) 는 분열(splitting)을 기반으로 하는 원초적인 방어기제는 정 체성 병리를 유발한다고 보았다.

높은 수준의 $\mathrm{BPO}$ 도 분열 기반의 방어기제를 사용하지만, 일상생활의 상당 부분에서 억압 기반의 방어기제를 사용하 여 비교적 안정된 기능을 유지하고, 여러 영역에서 잘 통합 된 경험을 유지한다. 그러나 심리적 갈등이나 스트레스 상황 
에서는 분열 기반의 방어기제가 갑작스럽게 작동하여 억압 방어기제를 압도하고, 통합된 정체성을 유지하지 못하며, 강 렬한 부분 대상관계를 경험한다.

정상 인격이나 신경증 수준의 인격구조 $(\mathrm{NPO})$ 의 경우도 때때로 분열 방어기제를 사용한다. 하지만 이미 잘 통합된 정체성과 자기 정체감을 가지고 있기 때문에 분열 방어기제 를 사용하더라도 내적/외적 현실에 대해서 심한 인격장애와 같은 극단화된 경험을 하지는 않는다(Caligor 등 2007).

\section{현실 검증력(Reality testing)}

낮은 수준의 $\mathrm{BPO}$ 는 매우 불안정하고, 급변하며, 혼란스 러운 대상관계를 경험하고, 분열(splitting)과 함께 부인(denial)의 방어기제가 함께 작용하기 때문에 대인관계 현실이 심각하게 왜곡되고, 전형적으로 행동화 경향을 보인다. 예를 들어 치료자를 이상적인 사랑의 대상으로 경험하다가도, 다 른 순간에는 견딜 수 없이 위협적이고 두려운 존재나 무가 치한 존재로 느낀다. 이들의 관계 경험은 매우 표면적이며 비현실적이다. 자신에 대해서도 전능감을 느끼다가 곧 무력 하고 취약한 존재로 경험한다. 이러한 극단적인 변화들이 서 로 분리된 채 경험될 때 자기와 대상에 대한 통합된 내적 대 상관계가 생겨나기 어렵고, 경험되는 극단적 대상관계는 맥 락화되지 못한다. $\mathrm{BPO}$ 환자들은 자신의 내적 경험을 다른 각도로 바라볼 수 없고, 극단적으로 경험하며, 매우 사실적으 로 느낀다. 그 결과 낮은 수준의 $\mathrm{BPO}$ 와 같이 심각한 인격 병 리를 가진 경우 일시적인 현실 검증력의 상실이 발견된다. 특 히 상당한 정서적 스트레스 상황이나, 알코올/약물남용 시에 심각한 현실 판단력 손실이 발생할 수 있다. 또한 $\mathrm{BPO}$ 환자 들은 부적절한 사회적 행동을 하면서 이것이 부적절하다는 사실을 인지하지 못하고, 사회적 신호에 대해 잘못된 해석을 하고, 일시적인 피해의식, 버림받는 느낌 등을 경험한다. 이 것은 현실 검증력이 상실된 것은 아니지만, 사회적 판단력 (social reality testing)의 장애에 따른 것이다.

\section{대상관계의 질(Quality of object relations)}

대상관계의 질 역시 구조적 진단에서 중요한 영역이다. '상호적이고, 친밀한 애착을 형성할 수 있으며, 유지할 수 있 는가?'에 대해 정상 인격의 경우 상대방의 필요를 이해할 수 있으며, 그것을 만족시킬 능력을 가진다. 서로 주고받는 상호 성에 기반을 두고, 상호 의존의 관계를 유지할 수 있다. 이러 한 성숙한 대상관계 능력은 Klein이 제시한 depressive position이라는 정신구조를 획득한 개인에게 가능하다. Klein은 다음과 같은 인격적 성숙이 일어날 때 depressive position을 획득한다고 기술했다. 첫 번째로 공격성에 대하여 투사하기
보다 자신의 책임으로 받아들여 자신의 파괴적 측면에 대한 죄책감과 우울을 경험할 수 있다. 두 번째로 자신과 대상이 분리되어 있다는 것을 새롭게 인식하고, 대상이 선하지만 완 벽하지 못하다는 것을 받아들이며, 이상적인 대상을 상실하 는 것에 대한 우울과 애도의 과정을 시작한다. 세 번째로 이 제 대상은 자신만의 삶과 욕구를 가진 통제할 수 없는 주체 라는 사실을 이해하게 된다(Klein 1975). 이러한 세 가지 심 리적 역량의 발달은 스스로를 제 3 자의 위치에 둘 수 있는 능 력(the triangulation)으로 이어져 오이디푸스 콤플렉스를 가 질 수 있도록 한다. 신경증 수준의 인격구조( $\mathrm{NPO}$ 를 가진 사람들 역시 상호적인 의존관계를 가질 수 있지만, 친밀하고 상호적인 관계에 성적 욕구(sexuality)가 온전히 통합되지 못 하는 양상을 보인다.

낮은 수준의 경계선 인격구조(low-level $\mathrm{BPO}$ )를 가진 경 우 대인관계는 일방적 욕구 충족의 양상이 지배적이다. 이들 은 “내가 무엇인가를 준다면, 당신도 나에게 무언가를 주어 야 한다. 나에게 특별한 만족을 주는 사람과의 관계가 다른 관계보다 횔씬 가치 있다.”라고 말한다. 이러한 특성은 원초 적인 방어기제를 사용하며 Klein의 paranoid schizoid position에 머무르는 환자들에게 발견된다. 반사회성 자기애적 인격을 가진 경우 모든 인간관계는 다른 사람을 이용하고 착 취하는 것을 중심으로 이루어진다. 한편 높은 수준의 경계선 인격구조를 가진 경우 이기적 관계 양상(self-serving orientation)을 가지지만, 최소한의 상호적 의존 능력을 가지고 있 으며, 그런 관계들을 유지해가는 능력을 가진다.

\section{도덕 기능(Moral functioning)}

정상 인격의 경우 도덕 기능은 일관되고, 유연하며, 도덕 체계가 자기 정체성에 잘 통합되어 있고, 이를 지키려 노력한 다. 신경증 수준의 인격구조의 경우도 잘 통합된 도덕적 체계 를 가지지만, 지나치게 높은 자기 기준, 가혹한 자기 비난 경 향성을 동반한 도덕적 경직성(moral rigidity)을 갖는 것이 특 징이다. 반면, 경계선 수준의 인격구조의 경우 다양한 스펙트 럼의 도덕 기능이 관찰된다. 한쪽 극단에서는 지나치게 경직 되어 있고 가혹한 자기 비난(self-criticism)을 하고 다른 사람 의 비난을 예상하면서 심한 불안과 주관적 고통감을 경험하 는 군이 있다. 다른 쪽 극단에서는 전혀 도덕적 기준을 가지 지 않고, 죄책감도 느끼지 않는다. 심한 자기애적 병리, 반사 회성 인격이 여기 해당한다. 또는 초자아의 통합이 온전히 이 루어지지 못하였기 때문에 한 사람 안에서 이 두 가지 모습이 혼재되어 나타난다. 즉, 때론 지나치게 가혹한 자기 비난도 있지만, 어떠한 영역에서는 전혀 죄책감을 느끼지 못한다. 


\section{인격구조의 수준과 무의식적 갈등(Conflictual motivations)}

앞서 요약한 다섯 가지 구조적 영역은 개인의 인격 병리 를 진단하는 데 매우 유용한 기준을 제시한다. 한편, Kernberg와 Caligor(2005)는 인격구조의 수준에 따라 개인이 갖 는 욕동, 소망, 심리적 갈등의 내용도 차이를 보인다고 주장 한다. 정상 인격이나 $\mathrm{NPO}$ 의 경우 심리적 갈등은 성적, 의존 적, 경쟁적, 공격적, 가학적 동기와 관련하여 드러난다. 예를 들어 "나는 화가 나는 감정을 말로 표현하지 않는다(경쟁적 인 감정, 적대적인 감정을 표현하지 않는다). 왜냐하면 내 말 을 들은 사람들은 나를 나쁜 사람, 사랑할 수 없는 사람이라 고 볼 것이기 때문이다. 나도 모르게 화나는 감정 등을 억압 하고 만다.”라고 말한다. 이 경우 자신에 대한 이미지는 비교 적 복잡하고 현실적이나, 공격적 충동은 배제되어 있다. 낮 은 수준의 $\mathrm{BPO}$ 의 경우 분열 기반 방어기제에 의하여 공격 성이 자아에 통합되지 못한다(Kernberg 1984). 이들의 주요 불안은 잘 통합되지 않은 공격성, 편집적 대상관계(paranoid object relations)와 관련된 강렬한 부정적 감정과 관련되어 있다. 부정적 대상(all-bad object)을 치료자에게 투사하고 강렬한 편집 불안(paranoid anxiety)을 경험하고, 대상에 대 해 가졌던 긍정적 대상관계 경험은 부정적 감정에 의해 압도 된다. 이전에 느겼던 긍정적 대상관계 이미지는 분리되어 (split off) 의식에서 사라진다(Bell 등 1988). 예를 들어 치료 자가 치료 시간을 늦게 시작하자 환자는 치료자가 자신을 좌절시키고, 화를 내게 했다고 느끼고 그것에 대해 몹시 분 노하게 되며, 자신의 분노도 정당한 반응으로 느낀다. 높은 수준의 $\mathrm{BPO}$ 의 경우 불안은 주로 친밀감과 의존에 관련된 것이 우선이며, 편집 불안은 이차적이다. 이들은 억압 기반 방어기제와 분열 기반 방어기제를 모두 사용하기 때문에 의 존성, 성, 자존감 유지의 문제와 관련된 갈등들이 공격성 관 련 갈등과 함께 압축(condensation)되어 나타난다. 갈등의 정도가 심한 영역(의존, 친밀감에 대한 두려움)에서 심각한 스트레스가 발생하면 억압 방어기제가 실패하고, 분열의 방 어기제가 압도하여 이차적으로 삽화적인 강렬한 격노, 미움, 편집증적 불안 등이 경험된다. 예를 들어 남자 친구와 상호 적이고 안정적인 관계를 가져오던 연극성 인격장애를 가진 젊은 여성 환자는 남자 친구에게 점차 의존하게 될수록 지 나치게 가까워져 경계를 침범당하거나, 모든 통제권을 남자 친구가 가져가고 무기력하게 버림받는 것에 대해 예민해지 고 불안정해진다. 이후 남자 친구가 자신이 원하는 만큼의 관심과 노력을 해 주지 않는다고 느낄 때 크게 실망하고, 사 소한 문제에도 강렬한 격노와 함께 남자 친구를 화나게 하 고 결국 관계를 단절하고 만다.

\section{구조적 진단의 임상적 함의}

임상가는 환자의 인격구조 수준에 따라 치료의 목표를 결 정해야 한다. Kernberg 등은 다음과 같은 치료 목표를 제안 한다. 경계선 수준의 성격구조 $(\mathrm{BPO})$ 를 가진 환자들의 경우 1) 정체성을 강화하고, 2) 해리되고, 이상화되고, 편집증적인 내적 대상관계를 통합하고, 3) 자신과 타인에 대한 경험이 보다 일관되고 분화되도록 돕는다는 것이다. 신경증 수준의 성격구조 $(\mathrm{NPO})$ 를 가진 환자들의 경우 1) 성격의 경직성이 줄어들도록 하고, 2) 갈등 영역에서 정서적 경험을 보다 풍 부하게 할 수 있도록 하며, 3) 억압되고, 해리된 내적 대상관 계가 자기 경험 안으로 들어오도록 돕고, 4) 갈등 영역에서 이전보다 유연하고 적응적인 기능을 할 수 있도록 돕는 것 을 목표로 해야 한다(Caligor 등 2018).

감정적으로 압도된 상황에서 신경증 수준의 인격구조나 경계선 수준의 인격구조를 가진 개인 모두 자기 관찰 능력이 저하되고, 주관적 경험이 외부 현실에 근거한 객관적이고 타 당한 것이라고 느끼게 된다. 하지만 신경증 수준 $(\mathrm{NPO})$ 의 환 자는 그 감정적 경험의 강도가 상대적으로 적고, 자기 관찰 능력, 현실 판단력 등을 동원할 수 있다(Caligor 등 2007). 이 들은 기본적 신뢰(basic trust), 상당한 정도의 자발성(autonomy), 공고한 정체감을 가지고 있고, 자존감 회복력이 있어 자신에 대한 불편한 내용을 경험해도 견딜 수가 있다. 때문 에 무의식적 내용에 대한 이해와 통찰을 돕는 정신분석적 치료 기법이 유용하다. 이들은 비교적 즉시 치료 동맹을 형 성하고, 관찰적 자아를 동원하여 무의식적 갈등, 방어, 환상, 믿음, 욕구 등에 접근해 간다. 치료자는 통찰과 갈등 해소를 위해 환자가 내적 갈등을 최대한 드러내도록 격려한다. 무의 식에 있는 장애물을 이해하고, 성숙한 방어기제를 갖게 함으 로써 일, 사랑, 놀이에서 최대한의 만족을 경험하도록 하는 것이 치료의 목표가 된다. 자신의 인격에 대한 자세한 이해 를 통해 최대한의 성장과 변화를 원하는 신경증 수준의 환 자는 정신분석이 권유된다(McWilliams 1994b).

반면, 심각한 경계선 인격구조 $(\mathrm{BPO})$ 를 가진 환자들의 경 우 더욱 구조화된 치료가 필요하다. 또한 공감, 치료자의 자 기 노출, 세팅의 유지 등을 통해 환자의 퇴행을 줄이는 방향 이 요구된다(McWilliams 1994b). 경계선 수준의 환자는 공 생적 애착과 적대적 분리 상태를 혼란스럽게 오간다. 이러한 자아의 불안정성 때문에 경계선 수준의 환자들을 치료할 때 는 특별히 명확한 치료 틀과 경계 설정이 요구된다. 일관된 시간, 장소뿐만 아니라, 경계와 관련된 무수히 많은 결정에 있어서 분명한 계약이 세워져야 하고, 일관되게 지켜져야 한 다(Langs 1973). 또한 경계선 인격구조 환자가 경험하는 강 렬한 감정과 공격을 견뎌주고 담아주는 노력(containment) 
이 대단히 중요하며, 이것이 치료의 주된 과정이 된다. 수년 간의 노력으로 환자가 치료자를 신뢰하고, 신경증 수준의 환 자가 맺는 것과 유사한 치료 동맹을 갖게 될 때까지 담아주 기는 지속되어야 한다. 대상관계에 따라 환자는 치료자에게 특정한 감정, 행동 등을 유발하려 한다. 치료자는 그 반응을 행동으로 옮기지 않고, 생각함으로써 담아준다(containing). 담아주기에는 두 가지 단계가 있다. 하나는 환자의 정서 상태 를 정확히 읽는 것이고, 두 번째는 역전이 반응을 통해 두 사 람 사이에 무엇이 일어나고(enacted) 있는지를 인식하여 감정 적 압력으로부터 정서적 거리를 유지하는 것이다. 이후 언어 적 해석이나 비언어적 반응을 통해 치료자는 환자의 대상관 계와 다른 새로운 경험을 하게 할 수 있다(Caligor 등 2007). 자신의 감정에 압도되지 않고, 사유할 수 있는 치료자의 능 력은 내재적으로 환자에게 전달된다. 그 결과 환자 자신도 특정 상황에서 정서적 압력에 압도되지 않고 사유할 수 있 다는 것을 알게 된다. 이것을 통해 정신화(mentalization)가 촉진된다(Fonagy와 Target 2003). 전이 해석은 신경증 환자 에서와 유사하지만, 혼란스러운 두 가지 감정 상태를 오가는 경계선 환자에게는 특별한 접근이 필요하다. 지금-여기에서 최근의 상황과 관련된 환자의 생생하고 즉각적인 감정을 다 루는 것이 필요하다. 해리되어 있었던 이상적 혹은 편집증적 대상관계(idealized/paranoid internal object relations)를 통 합하는 해석 과정(interpretive process)을 통해 자신과 대상 을 보다 일관되고, 안정적이며, 분화되고, 복잡하게 경험하 도록 돕는 것이 치료의 목표가 된다(Caligor 등 2009). 반면 경계선 환자에게 현재 감정 경험에 대한 기원적 해석(genetic interpretation)을 하는 것은 효과적이지 않다.

\section{논 의}

저자는 Kernberg와 대상관계 이론가들이 발전시켜 온 다 섯 가지 영역의 정신구조 진단 모델을 고찰하였다. Kernberg의 구조적 진단은 주요 정신분석이론들을 성공적으로 통합하고 있으며, 억압 방어기제를 기반으로 하여 고전적인 정신분석적 기법이 적합한 신경증 수준의 환자와 병적인 분 열 방어기제에 기반하여 정체성과 대상 항상성의 문제를 겪 는 경계선 수준의 환자를 구분하고 치료 계획을 수립하는 데 임상적으로 매우 유용한 진단 모델이다. 정신분석적 정신 치료에서 임상가는 환자의 인격 발달 수준에 맞는 현실적인 목표와 기대를 가져야 한다. 실현 가능한 목표는 환자를 좌 절로부터 보호하고, 치료자 자신도 소진되지 않게 한다. 따 라서 환자의 인격 병리와 구조의 수준을 정확히 진단하고, 치료 계획을 수립하는 것이 매우 중요하다. 한편 국내에서도
개인의 심리 내적 구조의 발달, 정체성의 확립, 자기 관찰 능 력과 조절 능력의 발달, 친밀한 관계를 형성하고 유지하는 능력의 성장 등을 의미 있게 촉진할 수 있는 치료 기법에 대 한 논의와 연구가 절실하다. 개인의 인격구조의 형성에 그가 속한 사회의 역사적 특성, 문화적 압력, 세대 간의 차이가 매 우 중요한 영향을 준다는 것은 의심할 여지가 없다. 한국 사 회는 급속한 외적 성장과 서구화 과정에서 강박적인 경쟁 문화, 전통적 위계적 가치관과 개인주의 충돌, 양극단의 이 념적 대립 등의 영향으로 자기애적 병리와 경계선 병리가 심화되고 있으며, 이러한 사회 병리의 압력은 개인이 자신만 의 고유하고, 건강한 정체성을 획득해 가는 것을 크게 위협 하고 있다. 따라서 향후 한국의 독특한 사회적 문화적 특성 이 개인의 정신구조 발달에 어떠한 영향을 미치는지에 대한 보다 면밀한 논의와 다각적인 연구가 필요할 것이다. 더불어 한국인의 인격구조의 특성을 더 체계적으로 진단할 수 있는 구조적 진단 체계의 개발은 이러한 논의를 더욱 촉진시킬 것이다.

\section{Conflicts of Interest}

The author has no potential conflicts of interest to disclose.

\section{ORCID iD}

In-Soo Lee: https://orcid.org/0000-0002-9944-9312

\section{REFERENCES}

Auchincloss EL, Samberg E. Psychoanalytic terms and concepts. New York, NY: American Psychoanalytic Association;2012. p.10-11.

Auchincloss EL. The psychoanalytic model of the mind. Washington, DC: American Psychiatric Publishing;2015. p.189-210.

Bell M, Billington R, Cicchetti D, Gibbons J. Do object relations deficits distinguish BPD from other diagnostic groups? J Clin Psychol 1988; 44:511-516

Caligor E, Kernberg OF, Clarkin JF. Handbook of dynamic psychotherapy for higher level personality pathology. Washington, DC: American Psychiatric Publishing;2007. P.125-148.

Caligor E, Diamond D, Yeomans FE, Kernberg OF. The interpretive process in the psychoanalytic psychotherapy of borderline personality pathology. J Am Psychoanal Assoc 2009;57:271-301.

Caligor E, Clarkin JF. An object relations model of personality and personality pathology. In: Clarkin JF, Fonagy P, Gabbard GO. Psychodynamic psychotherapy for personality disorders: a clinical handbook. Washington, DC: American Psychiatric Publishing;2010. p.3-35.

Caligor E, Kernberg OF, Clarkin JF, Yeomans FE. Psychodynamic therapy for personality pathology treating self and interpersonal functioning. Washington, DC: American Psychiatric Publishing;2018.

Donegan NH, Sanislow CA, Blumberg HP, Fulbright RK, Lacadie C, Skudlarski P, et al. Amygdala hyperreactivity in borderline personality disorder: implications for emotional dysregulation. Biol Psychiatry 2003;54:1284-1293.

Fonagy P, Target M. Psychoanalytic theories: perspectives from developmental psychopathology. London: Whurr Publishers Limited;2003. p. $270-282$.

Freud S. The standard edition of the complete psychological works of Sigmund Freud, Volume XIX (1923-1925): the ego and the id and other 
works. London: Hogarth Press;1923. p.1-66.

Greenberg JR, Mitchell SA. Object relations in psychoanalytic theory. Cambridge, MA: Harvard University Press; 1983.

Kernberg OF. A psychoanalytic classification of character pathology. J Am Psychoanal Assoc 1970;18:800-822.

Kernberg OF. Object-relations theory and clinical psychoanalysis. New York, NY: Jason Aronson;1976.

Kernberg OF. Severe personality disorders: psychotherapeutic strategies. New Haven, CT: Yale University;1984.

Kernberg OF, Caligor E. A psychoanalytic theory of personality disorders. In: Lenzenweger MF, Clarkin JF. Major theories of personality disorder. New York, NY: Guilford Press;2005. p.114-156.

Klein M. A contribution to the psychogenesis of manic-depressive states (1935). In: Klein M. Love, guilt and reparation and other works, 1921-1945. London: Hogarth Press;1975. p.262-289.

Langs RJ. The technique of psychoanalytic psychotherapy, Vol. 1: initial contact, theoretical framework, understanding the patient's communications, the therapist's interventions. New York, NY: Jason Aronson; 1973.

Lenzenweger MF, Clarkin JF. Major theories of personality disorder. New York, NY: Guilford Press; 2005.
McWilliams N. Psychoanalytic diagnosis: understanding personality structure in the clinical process. New York, NY: Guilford Press;1994a. p.53-66.

McWilliams N. Psychoanalytic diagnosis: understanding personality structure in the clinical process. New York, NY: Guilford Press;1994b. p.67-95.

Rapaport D. (edit. Gill MM). The collected papers of David Rapaport (1942-1960). New York, NY: Basic Books;1967. p.12.

Sugarman A, Jaffe LS. Toward a developmental understanding of the self schema. Psychoanal Contemp Thought 1990;13:117-138.

Sugarman A. Whatever happened to neurosis? Who are we analyzing? And how?: the importance of mental organization. Psychoanalytic Psychology 2007;24:409-428.

Vaillant GE. The wisdom of the ego. Cambridge, MA: Harvard University Press; 1993.

Wagner AW, Linehan MM. Facial expression recognition ability among women with borderline personality disorder: implications for emotion regulation? J Pers Disord 1999;13:329-344.

Westen D, Gabbard GO. Developments in cognitive neuroscience: II. Implications for theories of transference. J Am Psychoanal Assoc 2002; 50:99-134. 